
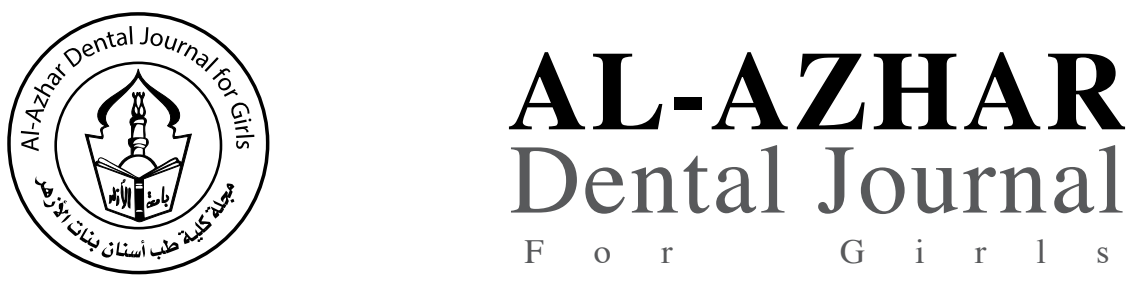

The Official Publication of The Faculty of Dental Medicine For Girls, Al-Azhar University Cairo, Egypt.

ADJ-for Grils, Vol. 3, No. 4, October (2016) — PP. 309:316

\title{
The Effect of Two Denture Base Materials on Microbial Colonization of Complete Dentures in Controlled Diabetic Patients
}

\author{
Sammar Mohamed ${ }^{(1)}$, Moustafa Mohamed Abdel Gany ${ }^{(2)}$, \\ Amany Ahmed Abdel Fattah ${ }^{(3)}$ and Dina Mahmoud kholif (4)
}

Codex : 08/1610

dentaljournal.forgirls@yahoo.com

\begin{abstract}
Aim: To compare between conventional heat cured Acrylic resin and Flexible thermoplastic resin denture base materials on microbial colonization of complete dentures in Controlled Diabetic patients. Material \& Methods: This study included thirty completely edentulous well controlled diabetic patients which were divided into two equal groups, fifteen patients received complete dentures made of conventional heat cured acrylic resin dentures while the other fifteen patients received upper complete denture made of flexible poly amide (Bre-flex 2ndedtion) thermoplastic dentures and lower heat cured acrylic resin denture. Oral swabs for isolation of microorganisms was done with gamma sterilized disposable swabs from tuberosity area under the fitting surface of the dentures, each swab cultivated in three culture media. Statistical analysis was performed for the results of this study to evaluate the microbial colonization in each of the two groups. Results: Candida was the most common isolate in acrylic resin group and was detected in 6 cases $(40 \%)$ and Streptococci were observed in 3 cases (20\%). Chi square test revealed a significant difference in the percentage of Candida species were the most common isolate in breflex group and were detected in 3 cases (20\%). Staph Aureus and Streptococci were observed in 2 cases each (13\%). Chi square test revealed a significant difference in the percentage of cases affecting by each type of microorganisms $(\mathrm{p}<0.00001)$.cases affecting by each type of microorganisms by $\mathrm{Cfu}$ $(\mathrm{ml}) x 102$. Conclusion: Flexible thermoplastic resin denture is thus a more predictable treatment modality as a denture base material due to its less microbial colonization and biological reaction in addition to its better esthetic appearance.
\end{abstract}

\section{INTRODUCTION}

Complete denture prosthesis involves the replacement of the lost natural teeth and the associated structures of the maxilla and the mandible ${ }^{(1)}$.

1. Dentist at Ministry of Health.

2. Professor of Removable Prosthodontics And Dean of Faculty of Dental Medicine For Girls, Al Azhar University.

3. Professor of Removable Prosthodontics and Vice Dean of Faculty of Dental Medicine For Girls, Al Azhar University.

4. Assistant Professor of Removable Prosthodontics, Faculty of Dental Medicine For Girls, Al Azhar University. 
The causes of dissatisfaction with complete dentures are related to appearance, pain, difficulties during eating, instability and lack of retention. They include not only the quality of the dentures and the oral condition, but also patient related factors such as debilitating diseases as diabetes and their attitude toward dentures ${ }^{(2)}$

Diabetes mellitus is one of the most prevalent diseases worldwide and is commonly found in dental patients. Patients with a diagnosis of diabetes mellitus present a higher susceptibility to infections due to a deficiency in polymorphonuclear leukocytes, as a result of vascular alterations and neuropathies ${ }^{(3)}$. An increased risk of infections has been observed with reduced salivary flow, low salivary buffering capacity ${ }^{(4)}$, and inadequate hygiene of the complete dentures ${ }^{(5)}$.

Acrylic resin was the most employed material in complete denture bases, ${ }^{(5)}$ due to its simplicity in processing and its lower cost, however it has disadvantages as inadequate tensile and compressive strength and possible allergic reaction.

With the development of new denture base materials, flexible biocompatible thermoplastic denture base material was introduced into dentistry with its unique physical and esthetic properties, to overcome too much of the limitations found in conventional acrylic resin, since it offered better denture adaptation as well as denture retention because of its light weight and because of engaging more desirable undercuts. Esthetics was also provided by this material. ${ }^{(6)}$ The aim of this study was to compare between conventional heat cured acrylic resin and flexible denture on microbial colonization in controlled diabetic patients

\section{MATERIAL AND METHOD}

Thirty completely edentulous patients were selected from the Outpatient Clinic of Prosthodontic Department. Faculty of Dental Medicine for Girls Al-Azhar University according to the following criteria:
1. The selected patients had well developed ridge covered with firm mucoperiostium.

2. All patients had Angle's class I.

3. All patients were male at the age range from 5060 years old.

4. All patients were free from any TMJ disorder.

5. All patients had sufficient inter-arch space.

6. All patients were controlled diabetic.

7. All patients were in good oral hygiene.

8. All patients were free from debilitating systemic diseases that might increase the microbial adhesion as AIDS, Anemia ....etc.

9. Smoker patients or those receiving any medication other the hypoglycemic drugs were excluded from this study.

10. All patients informed about practical steps of this study and signed approval consent.

Patient examination was made including; blood investigations, extra oral examination, intraoral examination, radiographic examination and diagnostic casts

Patients selected were randomly divided into two equal groups each composed of 15 patients.

\section{Group I:}

All patients received upper and lower complete denture that both made from heat cured acrylic resin. Maxillary and mandibular preliminary impressions to obtain study cast and special tray. Zinc oxide eugenol paste was used to make final impression, and rubber base impression material to obtain master cast, the trial acrylic denture bases with wax occlusion rims were constructed on the upper and lower master casts. Maxillary cast was mounted on semi adjustable articulator using maxillary face bow, centric jaw relation was made using wax wafer technique, the lower cast was mounted on the articulator using the centric jaw relation record taken from the patient. Waxing up was done, and the 
waxed up denture was cheeked in the patient mouth. Then, flasking, wax elimination was done in the usual manner. The dentures were processed using conventional heat-cure acrylic resin. Deflasking, finishing and polishing of the dentures were done following the conventional routine method.

\section{Group II:}

All patients received upper and lower complete denture, the upper made from metallic meshes covered by thermoplastic resin (bre.flex2) and lower denture made from conventional heat cured acrylic resin. The maxillary, mandibular primary and secondary impression and master cast were made as group I. The master cast was duplicated into refractory cast (investment cast), to fabricate the metal framework. Wax pattern of the framework was done on the investment cast. Spruing, burn-out of the pattern was done forming a mold into which the molten casting metal was flown into it. The metal base finished and polished. Metal-try in patient mouth was done. Record block made over the metal frame work. Bite registration and mounting on semi adjusted articulator as in group I was done. Setting up of artificial cross linked acrylic resin teeth were mechanically attached to this type of denture base material. The mechanical means of retention were prepared in artificial teeth before setting as follows:

a. Circumferential groove in the cervical area around the neck of the anterior and posterior teeth were prepared, pressed into the denture base material. b. A mesio-distal groove was made in the base of both anterior and posterior teeth.

After completing the arrangement of the artificial teeth; the waxed-up denture base were tried in patient's mouth. Special types of flasks were used with thermopress complete denture base materials. According to the manufacture`s instruction, during flasking, the injection channels were attached as close as possible to the injection opening of flask. Complete dentures were prepared with the set-up teeth to being finally invested in the flask. The flask was placed in boiling water for wax elimination like the conventional technique with heat cure acrylic resin base material, then the flask was closed, the thermopress acrylic resin was supplied in the form of crystals. This supplied material is called (thermopress 400 system).Fig1:a,b

The thermopress complete denture was processed with the injection molding technique. The (Start-Heating) key was pressed to start melting the cartridge with its crystal to $222^{\circ} \mathrm{c}$ for 15 minutes. After the crystal melt, the (Start-Injection) key was pressed to inject the material into the denture mould of the flask through the sprue channel. Once the injection was completed the system stood for minutes then the piston was allowed to move backward and the flask was removed from the machine by pressing the (Eject) key. The flask deflasked, then they were ready for finishing and polishing by using thermal resin finishing burs at low speed, pumice, and finally buffing was done to add a very high luster. After that they were ready for insertion.

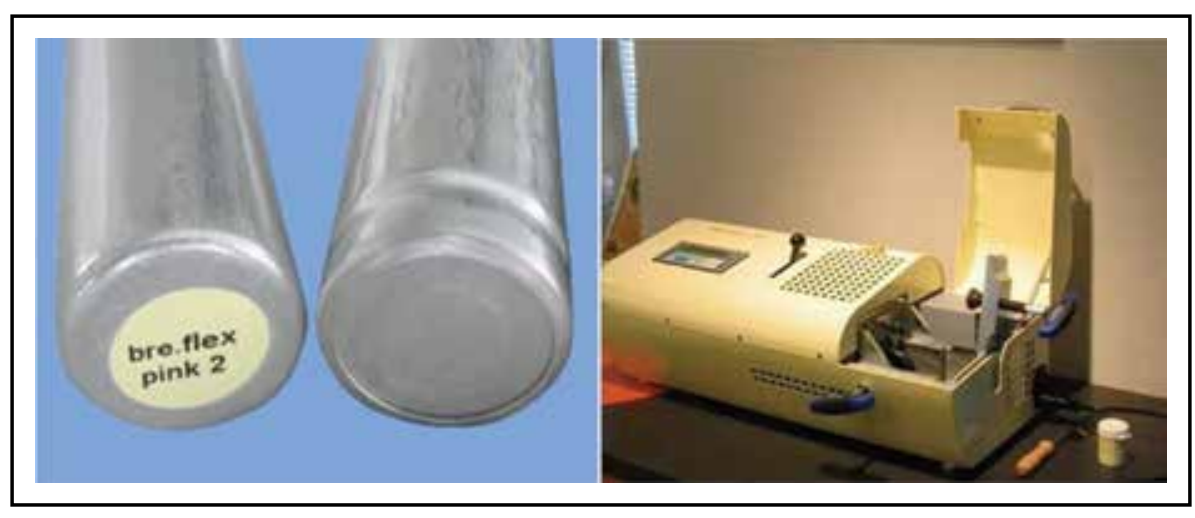

Fig. (1) (a)Bre-Flex cartridge

(b) Thermopress 400 system 
The lower denture in this group was made from conventional heat cured acrylic resin as in group I.

\section{Isolation of microorganisms and mucosal swabs:}

The isolation of microorganisms was done with gamma sterilized disposable swabs. Swabs were taken from the tuberosity area of the palate under the fitting surface of the denture immediately after insertion of the denture and after 3,6 and 9 months by vigorous strokes over the mucosa form distance of 1 to $2 \mathrm{~cm}$ for 30 second. Cultural method:

It is a method for diagnosis of microorganism which can grow well on an artificial media. It is also considered the initial step in studying its morphology and subsequent its identification. Each swab cultivated in three culture media; Sabouraud agar, MacConkys agar and blood agar.

\section{Culturing and incubation procedure:}

Sterile tubes were filled with sterile saline. Six sterile tubes were used for each sample. The first tube of the five was filled with $1000 \mu \mathrm{L}$ of sterile saline, and the other four were filled with $900 \mu \mathrm{L}$.
Identification and counting of the colonies:

After 24 hours the plates were removed from the incubator. The counting was done by counting the number of colonies that appeared on the Petri dish (Colonies forming units per sample) (CFU)/ sample). Counting was done on the Petri dish in the countable dilution by visual eye and permanent marker. Then converted into $\mathrm{CFU} / \mathrm{ml}$. The total number of colonies per stimulated saliva sample was determined by the following equation:

$\mathrm{CFU} / \mathrm{ml}=$ total number of colonies counted in the plate $\mathrm{X}$ inversion of the saline dilution $\mathrm{X}$ inversion of the cultured volume X 1000 .

\section{Statistical Analysis}

Statistical analysis was performed with SPSS 16. The significance level was set at $\mathrm{P} \leq 0.05$. (ANOVA) Test was used to variance and compare between the two types of complete denture. (Chi square test) was used for comparison between groups when ANOVA test is significant.

\section{RESULTS}

The results of this study revealed that

Comparison between microorganism mean count cfu/ml among two studied groups was presented in table(1):

\begin{tabular}{|c|c|c|c|c|c|c|c|c|c|}
\hline \multirow{2}{*}{ Organism } & \multicolumn{4}{|c|}{ Acrylic mean $(\mathrm{cfu} / \mathrm{ml})$} & \multicolumn{4}{|c|}{ Preflex mean $\mathrm{cfu} / \mathrm{ml}$} & \multirow{2}{*}{$\begin{array}{c}\text { P value } \\
\text { (ANOVA } \\
\text { test) }\end{array}$} \\
\hline & On ins & $3 \mathrm{~m}$ & $6 \mathrm{~m}$ & $9 \mathrm{~m}$ & On ins & $3 \mathrm{~m}$ & $6 \mathrm{~m}$ & $9 \mathrm{~m}$ & \\
\hline Staph & 70 & $3.8 \times 10^{2}$ & $40 \times 10^{2}$ & $50 \times 10^{4}$ & $1 \times 10^{2}$ & $4 \times 10^{3}$ & $5 \times 10^{4}$ & $7 \times 10^{4}$ & $<0.00001^{*}$ \\
\hline Strept & $1.33 \times 10^{2}$ & $3 \times 10^{3}$ & $5 \times 10^{3}$ & $35 \times 10^{3}$ & 0 & $2.33 \times 10^{2}$ & $2.67 \times 10^{2}$ & $4 \times 10^{2}$ & $<0.00001 *$ \\
\hline Candida & $0.7 \times 10^{2}$ & $4 \times 10^{2}$ & $4 \times 10^{3}$ & $5 \times 10^{5}$ & 0 & $2 \times 10^{2}$ & $16 \times 10^{2}$ & $22 \times 10^{2}$ & $<0.00001^{*}$ \\
\hline $\begin{array}{c}\text { Mix } \\
\text { (staph, candida) }\end{array}$ & $\begin{array}{l}0 \\
0\end{array}$ & $\begin{array}{l}3 \times 10^{2} \\
2 \times 10^{2}\end{array}$ & $\begin{array}{l}4 \times 10^{2} \\
4 \times 10^{2}\end{array}$ & $\begin{array}{l}2 \times 10^{2} \\
5 \times 10^{2}\end{array}$ & 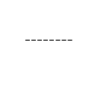 & -..-- & -..-- & -נו- & -..-- \\
\hline $\begin{array}{c}\text { Mix } \\
\text { (Strept, candida) }\end{array}$ & $\begin{array}{c}0.67 \times 10^{2} \\
1.6 \times 10^{2}\end{array}$ & $\begin{array}{l}4 \times 10^{2} \\
5 \times 10^{2}\end{array}$ & $\begin{array}{c}5 \\
\times 10^{3} \\
7 \times 10^{2}\end{array}$ & $\begin{array}{l}7 \times 10^{3} \\
5 \times 10^{3}\end{array}$ & -..- & $\ldots$ & 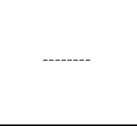 & $-\ldots$ & -.-- \\
\hline $\begin{array}{c}\text { Mix } \\
\text { (strept, kell) }\end{array}$ & $\begin{array}{l}0 \\
0\end{array}$ & $\begin{array}{c}1.67 \times 10^{2} \\
0\end{array}$ & $\begin{array}{c}2.33 \times 10^{2} \\
0\end{array}$ & $\begin{array}{c}33.3 \times 10^{2} \\
2.5 \times 10^{2}\end{array}$ & $\begin{array}{l}0 \\
0\end{array}$ & $\begin{array}{c}2 \times 10^{2} \\
0\end{array}$ & $\begin{array}{c}3 \times 10^{2} \\
0\end{array}$ & $\begin{array}{c}5 \times 10^{2} \\
1.5 \times 10^{2}\end{array}$ & $<0.00001 *$ \\
\hline
\end{tabular}

* Statistically significant 


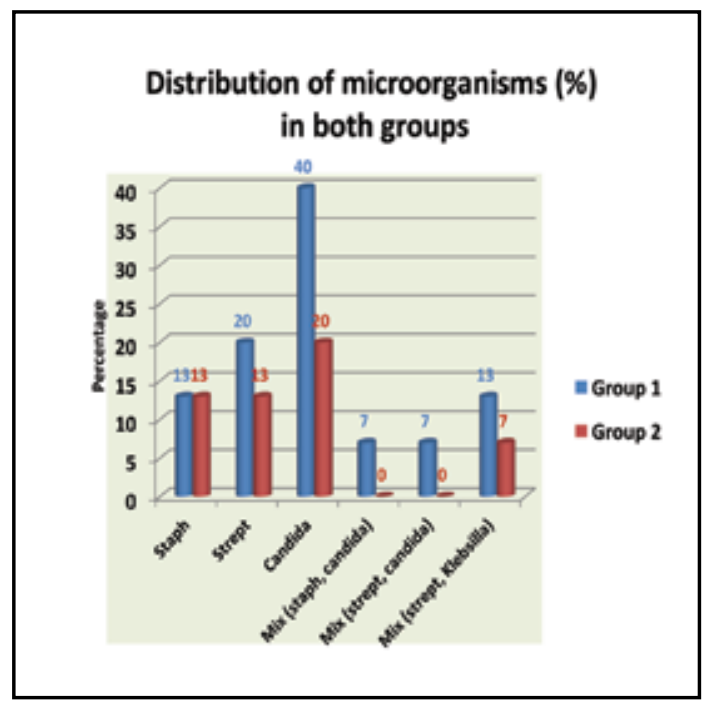

Fig. (2) Distribution of microorganism in both group.

\section{Prevalence and count:}

As regard prevalence and count of organism of two studied groups, the acrylic group had a higher risk for microbial colonization, mainly (candida $40 \%$ ) followed by (strept $20 \%$,mix $13 \%$ ). On other hand microbial colonization of breflex showed highly statistical lesser as show (candida 20\%), followed by (strept 13\%, mix 7\%).

\section{- Denture induced stomatitis}

The prevalence of denture induced stomatitis in group 1 (acrylic) was 40\% (6 cases), whereas in group 2 only one case was observed (6.7\%). Moreover, denture induced stomatitis occurred earlier in group 1 (at 6 months observation time), compared to group 2 (at 9 months). Chi-square test revealed that the difference was extremely statistically significant $(\mathrm{p}<0.00001) 0$ (figure 3 ).

\section{DISCUSSION}

Thirty male diabetic patients were selected in this study to assess the amount of microbial colonization that can adhere to denture fitting surface of acryl and breflex used in such patients, several criteria as sex, age, health state and others were taken

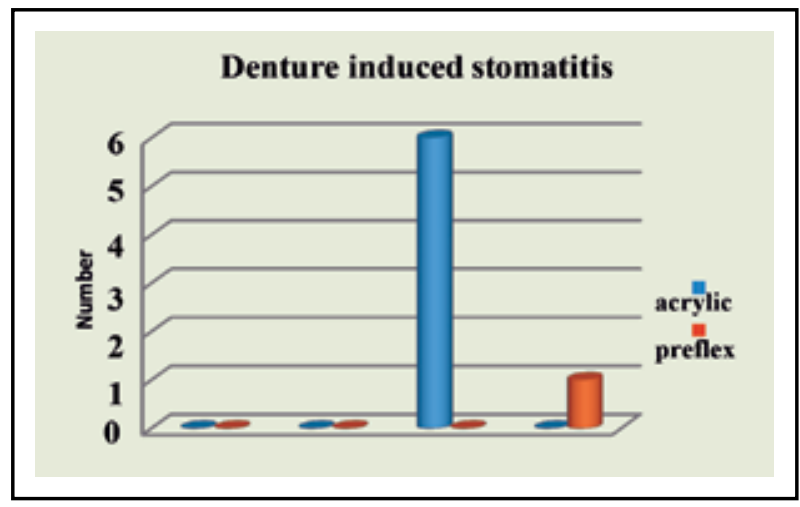

Fig. (3) Number of denture induced stomatitis cases among the studied two group

into consideration. In this study the patient were chosen to be diabetic due to the increased prevalence of diabetes mellitus as it affected approximately 140 Million individuals ${ }^{(7)} \cdot$ Only controlled diabetic patient were included in this study to keep blood glucose level as close to normal as possible which can be life saver ${ }^{(8)}$. The age range was from 50 to 60 as older patient have potentially, more systematic health factor, more problems adapting to new prostheses and more liability decreased to alveolar bone loss that occurs with advanced age. As well as to eliminate the effect of age changes on microbial oral flora ${ }^{(9)}$. Male patients were selected to avoid the effect of sex hormones on the oral flora which lead to change in $\mathrm{pH}$ of saliva and affect ratio of micro- organism ${ }^{(10)}$ Non smoker patients were selected for this study as smoking may cause a mild, clinically undetectable alternation of the oral mucosa and facilitate contributory factor in the pathogenesis of oral Candida in diabetic patients. None of the patients were receiving antibiotics, corticosteroids, antihistamines, sedatives and hypnotics during the whole follow up period which cause decrease of the salivary flow poviding a suitable environment for mucosal inflammation and infection ${ }^{(11)}$. The upper denture was chosen for sampling rather than the lower denture as the accumulated biofilm on the fitting surface of the lower denture may be displaced by salivary flow and movement of the denture thus detection of bacterial and candidal colonization on 
the fitting surface of the maxillary denture was expected as it acts as a barrier that prevents salivary cleaning. Acrylic resin was used for the denture base construction ${ }^{(12)}$. The most common material was the polymethyl methacrylate polymer (PMMA) supplied in different forms and methods of curing ; however, it has many disadvantages ${ }^{(13)}$.

In this study the combination design of the denture was done by using metal covered by flexible resin (bre-flex), due to the flexible resins were developed for construction of provisional prostheses such as immediate RPDs, as reported by Shamnur et $\mathrm{al}^{(14) .}$ otherwise it will break. The material has good flexibility like titanium, which allows it to return back to its original shape and position after a little bend, allow the use prosthesis with little adjustment, and more comfortable to the patients. Swabs were taken from the upper dentures by rubbing once for a distance of 1 or $2 \mathrm{~cm}$, however, to ensure a more accurate and standardized isolation procedure. The rubbing was done for a specified period of time 30 seconds.

In this study comparison was done between conventional heat cured A.R. and thermoplastic resin(bre-flex) regarding microbial colonization From the analysis of all result of this study, it was evident that group I showed marked increase in all of clinically investigated parameters throughout the different follow up periods relative to group II.

As was shown in the result of this study there was statistically significant difference in candidal growth between the two groups. In group II less candidal colonization was observed. This could be attributed to biocompatibility of these material as they are proved by many authors to have few or no residual monomer ${ }^{(15)}$. Which enabled this material to be a substitute for PMMA especially with patients who are allergic to monomer. This biological advantage might be due to their way of processing that occurs by injection of pre polymerized resins under temperature and pressure without chemical reaction ${ }^{(16)}$
Moreover in group II patients the mean value of microbial colonization is lower. As explained by Thakral et al, ${ }^{(17)}$ the flexibility of materials changed the concept of force control from the design features of the appliance to the properties of the base material. This material provide stress breaking action and allowing better stress distribution, act as a tissue conditioner in the long term use due to its slight movement as a result of flexible nature which might allow normal blood circulation underneath it and reduce the tissue atrophy that occur to the non loaded edentulous ridge ${ }^{(18)}$. This results was attributed with Leticia et al ${ }^{(19)}$, who found that the colony counts of Candida species were high in the acrylic resin denture bases in HIV patients. Due to surface irregularities of acrylic resin, a factor that assist in the entrapment of microorganism.

The findings of the current study were also in agreement with observation of $\mathrm{He}$ et al ${ }^{(20)}$ who found that candidal adherence to denture base acrylics differs depending on the quality of the acrylic used as well as the Candida species in question .Heat-cured resins in general tended to have significantly lesser numbers of yeast attached than cold-cured resins, due to variation of surface free energy and hydrophobicity, roughness of acrylic surface is also an important factor in adhesion.

The acrylic denture fitting surface cannot be mechanically polished and thus presents irregularities and microscopic pores that facilitate bacterial and fungal colonization, the denture may cause trauma to the palatal mucosa, which reduces tissue resistance to infection and increases mucosa permeability, contributing to the passage of toxins produced by the microorganisms. ${ }^{(22)}$

Nikawa, ${ }^{(23)}$ found that fungal colonization was the lowest colonization that observed with additional silicone materials, soft acrylic liners with visible light curing. This finding is in agreement with previous study. 
However another authors, conclude that saliva was capable of reducing the adherence of Candida species, whereas roughness and free energy did not influence the adherence rates. The polymerization method heat versus microwave, did not influence Candida species adherence values. ${ }^{(24)}$ This conclusion is contradicted with this study.

Sobolewska et al, ${ }^{(25)}$ found that Microbial colonization to the Co-Cr denture base was more than its colonization to acetal resin denture base, the smallest adhesion to the materials was shown by Candida albicans . The acetal resin may have an ionic surface charge which facilitates adsorption of salivary defense molecules such as histamines and defensins.

Increased microbial colonization in group I, could be due to changes on surface details of material which resulted in a very rough surface with many cracks in the material thus provided a larger surface area and more protected environment for colonization this may be a reason for the replacement of material by time. ${ }^{(26)}$

Study reported that microbial proliferation and adherence on the polyamide denture base material(thermoplastic resin) was higher than that of acrylic due to its difficulty in polishing (using conventional polishing methods), ${ }^{(27)}$ the result of this study is contradicted with previous study.

Thus, the result of this study was found to be in agreement with the experimental result reported by Morgan TD, ${ }^{(28)}$ show that the type and roughness of acrylic used had a significant effect on the adhesion of primary colonizer, Strept Orali, among all microorganism tested, Streptococcus sanguis andporphyromonas gingivalis were found to have the most adherence to acrylic denture base.

In this study, thermoplastic material helped the diabetic patients to use their dentu dentures but the degree of satisfaction was different according to the material used. Bacterial colonization and candidal growth also varied with materials used

\section{CONCLUSION}

Flexible dentures made of thermoplastic resin yielded better results and more favorable biological reaction than the acrylic resin dentures throughout the study period and less microbial colonization. In addition, thermoplastic resin is light in weight and biocompatible as it is hypo allergic and less denture induced stomatitis observed with it. Flexible thermoplastic resin denture is thus a more predictable treatment modality as denture base material due to its less microbial colonization, biological reaction in addition to its better esthetic appearance.

\section{REFERENCES}

1. Goiato MC, Riberio PD, Garcio AR, Dos Santos DM. Complete denture masticatory efficiency. J Calif Dent Assoc. 2008; 36 (9): 683-6.

2. Leon B L, cury A A , Garica M R. Water sorption, solubility and tensile bond strength of resilient denture lining materials. J Prosth Dent.2005; 93: 282.

3. Orsi L A, Andrade V C. Effect of chemical disinfectant on the transverse strength of heat polymerized acrylic resins submitted to mechanical and chemical polishing. J Prosth Dent.2004; 92: 382.

4. Orsi L A, Andrade V C. Effect of chemical disinfectant on the transverse strength of heat polymerized acrylic resins submitted to mechanical and chemical polishing. J Prosth Dent.2004; 92: 382.

5. Emel D. Clinical assessment of common patients complains with complete denture. J. Prosth Dent. 2002; 10: 204

6. Varon F, Mack S L. The role of dental professional in diabetes care.J Contemp Dent Prac.2000;1: 1-27

7. Danielle Cristina de Lima, et al. Oral manifestation of diabetes mellitus in complete denture wearers. J Prosth Dent.2008;99:60-5.

8. Melander A. Oral Anti-diabetic drugs. An overview Diabet Med. 1996;13:143.

9. Al Dwairi ZN. Prevalance and risk factors associated with denture related stomatitis in healthy subjects attending dental teaching hospital in north Jordan. J Dentistry Assoc. 2008;54:80-3.

10. Manfredi M, Culloug MJ, Al- Karaawi ZM. The isolation, identification and molecular analysis of candida Spp. Isolated from oral Cavities of patients with diabetes mellitus. Oral Microbial Immunal.2002;17:181-5. 
11. Soysa NS, Samaranayake LP, Ellepola AN. Diabetes mellitus as a contributory factor in oral candidosis. Diabet Med. 2006; 23:455-9.

12. Edgerton M, Levine MJ. Characterization of acquired denture pellicle from healthy and stomatitis patients. J prothet Dent. 1992;68(4):683.

13. Edgerton M, Levine MJ. Characterization of acquired denture pellicle from healthy and stomatitis patients. J prothet Dent. 1992;68(4):683.

14. Shamnur SN, Jagadeesh KN, Kalavathi SD, Kashinath KR. Flexible dentures -an alternate for rigid denture ?. J of Dent Scien and Res.2005;1(1):74-9.

15. Lygre H, Solheim E, Gjerdet NR. Leaching from denture base materials in vitro . Acta odont Scand . 1995;53:75

16. Bortun C, Lakatos S, Negrutiue M, Ardeleean L. MetalFree Removable Partial Dentures made of Thermoplastic Material.TMJ 2006;56(1):80-7.

17. Thakral GK, Aeran H, Yadav B, Thakral R, Flexible partial dentures-A hope for the Chllenged Mouth. Peoples J of Scient Res. 2012;5(2):55-9.

18. Singh JP, Dhiman RK, Bedi RP, Girish SH, Flexible denture base matrial: Aviable alternative to conventional acrylic denture base material. Contemp Clin Dent. 2011; 2(4):307-13.

19. Leticia FP, Gene CS, Catherine MF, et al. The effect of complete dentures with a metal plate on candida species grouth in HIV - Infected patient. J of Prosth. 2006;15(2):306-15.
20. He XY, Meurman HJ, Kari K, Rautemaa R,et al. In vitro adhesion of candida species to denture base material.Blak well pub ltd. 2005;49:80-4.

21. Jagger DC, Al-Akhazami I, Harrison A, Ress JS. The effectiveness of seven cleansers on tea stain removal from PMMA acrylic resin . Int J Prosth. 2002;15:549-52.

22. Nikawa H, Chen J, Hamada T, et al. Candida albicans colonization on thermal cycled maxillofacial polymeric materials in vitro. J of Oral Rehab .2001;28:526 -33.

23. Juliana SM, Wander JDS, TatianaP,et al. Influnce of acrylic resin polymerization methods and saliva on the adherence of four candida species. J prosth Dent.2006;96:205-11

24. Sobolewska E, Fraczak B, Czarnomysy FD, Eychmielewska H, Karakulska J. Bacteria adhesion to the surface of various prosthetics material. Ann Acad Med Stetin. 2007;53:68-71.

25. Mustafa MM, Serra Oguz, Finn F, Erik S, Arife Dogan, etal. A prospective study on the clinical performance of polysiloxane soft liners : one-year study result, Dent mater J. 2008;27(3):440-47.

26. Abuzar MA, Bellur S, Duong N, Kim BB, Lup, Palfreyman $\mathrm{N}$. Evaluating surface roughness of a polyamide denture base material in comparison with poly (methyl methacrylate). J Oral Sci. 2012;52(4):577-81

27. Morgan TD, Wilson M. The effect of surface roughness and type of denture acrylic on biofilm formation by streptococcus oralis in a constant depth film fermentor.J of App Microbilogy. 2001;91:47-53. 